\title{
The Role of Middle Managers in Realising Human Resource Strategy : Evidence from the NHS
}

\section{[Middle Managers and Human Resource Strategy]}

\begin{abstract}
The long-standing debate about the role of middle managers in human resource strategy reflects a wider debate about their role in organizations generally. On one side, commentators suggest that their role is merely to implement deliberate strategy; on the other, there is a growing body of literature that suggests middle managers can take on an enhanced role in strategic change. It is in this debate that our study is located. The case study reported upon in this chapter builds upon previously published work that examined the influence of middle managers upon strategic change in the NHS [Currie, 1999a, 1999b, 2000; Procter and Currie, 1999]. Our objective is to throw light upon the possibility of an enhanced role for middle managers in the area of human resource strategy. To do this we draw upon the strategic change literature and, in particular, the typology of middle management involvement developed by Floyd and Wooldridge [Floyd and Wooldridge, 1992, 1994, 1997]. The chapter is in four parts. In this first part, as well as outlining the conceptual framework, we consider the interaction of middle managers with the personnel function. The second part introduces the case-study organization and locates it within its context. The third presents the findings of the case study. Finally, in our discussion and conclusion we return to the issues raised at the start of the paper, showing how our analysis deepens understanding of the interaction of middle managers with the personnel function in the realization of human resource strategy.
\end{abstract}




\section{INTRODUCTION}

\section{The Interaction of Personnel with Middle Managers in the NHS}

The discussion of the interaction of middle or line management with the personnel function was fuelled by the debate about the emergence of human resource management [Poole 1990; Sisson 1990; Storey 1992]. Storey, for example, says that 'contrary to speculative reports about the demise of the middle manager, occupants of these roles were exercising authority across a greatly expanded territory' [1992: 214].

More recently, the idea that the personnel function carries out its role in collaboration with line managers has gained more prominence from publicity afforded to Ulrich's [1997] book, Human Resource Champions. Ulrich sets out multiple roles that the personnel function should take on. These are operational as well as strategic, with the potential for the latter dependent upon effective discharge of the former. This model carries with it implications for the personnel professional's relationship with line management. Most importantly, Ulrich recognises the role line managers can play in the delivery of HR policy. Thus although in this model the personnel function is responsible for the accomplishment of the deliverables, it does not have to do all the actual work. Instead, the work will be shared to a significant extent with line managers.

Ulrich's framework for realizing human resource strategy has been highlighted as a prescriptive model for the personnel function in the NHS by Hugh Taylor, its Director of Human Resources, in numerous speeches across the country to health service personnel practitioners. Despite this, it does not appear to be the case that the importance of middle managers, as part of the cadre of line managers, is recognized by the personnel function in the NHS. 
The process of reform following the Griffiths Report [DHSS, 1983] appeared to offer both the personnel function and middle managers a good chance to take on a more strategic role. The role of management was in general being enhanced, trusts were being established and were encouraged to act autonomously, and labour costs, flexibility and pay were high on the agenda. However, a more strategic role for the personnel function went unrealized [Bach 1994; Caines 1990; Guest and Peccei 1992, 1994), as did an enhanced role for middle managers. Important in this were attacks upon middle managers in the NHS since the mid-1990s [Hancock, 1994; Health Service Journal, 1994a, 1994b], which reflect more general organizational trends to restructure and 'thin out' layers of management [Drucker 1988; Kanter 1989; Peters 1987, 1992]

What has not been apparent in the NHS is the hope expressed by, amongst others, Frohman and Johnson [1993] and Smith [1997], that, following de-layering, the remaining middle managers can have an enhanced role. To illuminate this within the area of human resource strategy we turn to the strategic change literature and the typology of middle management involvement developed by Floyd and Wooldridge [1992, 1994, 1997].

\section{The Conceptual Framework}

Approaches to strategic change in the NHS have traditionally separated the formulation of strategic change from its implementation, with the former remaining the preserve of executive management. As a result there has been little consideration of a role for middle managers beyond that of merely implementing deliberate strategy. In contrast, a processual approach [Mintzberg and Waters 1985; Pettigrew et al. 1992), in which strategy represents a set of pragmatic 
compromises between various stakeholders in the organization [Pettigrew, 1985], allows for a much greater middle management role.

Floyd and Wooldridge's framework [1992, 1994, 1997] is useful in classifying the forms this role can take. They outline a typology of involvement in strategic change which distinguishes between upward and downward influence. In terms of upward influence, the roles taken on by middle managers are 'championing alternatives' [see also Kanter 1982 and Burgelman, 1983a, 1983b] and 'synthesising information' [Nonaka 1988]. The former is seen as a product of ideas divergent from organization thinking, whereas the latter is more integrative, since middle managers interpret and evaluate information concerning internal and external events. As regards downward influence -- that is, the carrying out of strategy [Schilit 1987; Schendel and Hofer 1979] -- middle managers 'facilitate adaptability' and 'implement deliberate strategy'. The former may be divergent, since here the middle manager is concerned to nourish adaptability apart from the plans embedded in deliberate strategy [Bower 1970; Kanter 1983]. The latter is often considered the key strategic role of middle managers [Nutt 1987; Schendel and Hofer 1979] and is defined as managerial interventions that align organizational action with strategic intentions.

\section{THE CASE}

Our case study organization, Edwards Hospital, is an acute hospital. Its annual budget at the time of data-gathering was $£ 114$ million and it employed around 5000 staff. Edwards Hospital is structured around 32 clinical directorates and 5 nonclinical directorates.

We can define middle managers as those who 'mediate, negotiate and interpret connections between the organization's institutional (strategic) and technical 
(operational) levels' [Floyd and Wooldridge 1997: 466]. A distinction is necessary between those middle managers that work within specialist functions, such as marketing and human resources, and those who work within operations but also perform the co-ordinating role. This chapter focuses upon the latter, a group which in Edwards Hospital consists of 32 Clinical Directors, 13 Specialty Managers and 12 Nurse Managers. Respresentatives of this group were interviewed in three directorates of the hospital.

This chapter reports upon findings from one of these, the Theatres Directorate, and of particular interest is a major human resource intervention in this area, the so-called Theatres Project. This involved the harmonisation of terms and conditions of the nurses and the theatre practitioner (ODAs), two groups of employees who essentially carried out similar jobs. The harmonisation was achieved by implementing competence-based job descriptions and a new local pay scheme.

The personnel function in Edwards is called the Human Resources (HR) Department and is headed by a Director of Human Resources. He has a place on the trust board alongside five other executive directors and the chief executive. He does not have voting rights at board meetings, although, as he explained, 'it rarely comes to this'. Much of the responsibility for the relationship between the personnel function and middle managers lies with the Personnel Manager, who reports into the Director and deputises for him when necessary. Into the Personnel Manager report three Personnel Advisors, who spend much of their time out in the directorates to which they are attached, working alongside middle managers.

Formal human resource strategy is set out in a document, Human Resource Strategy 1998-2003. Key themes are identified, and this is followed by some more specific objectives. A statement within the strategy document outlines the role of the 
corporate centre and emphasizes that middle management contribution is crucial to its realisation:

\begin{abstract}
A strategy should describe a method of achieving certain aims and objectives as well as describing those aims and objectives. The implementation of the strategy is the responsibility of numerous managers within the Trust who have responsibilities for human resources. There are certain aims that will only be achieved if corporate action is taken and the role of the Human Resources Department will be to ensure that action is taken when necessary and to give the appropriate support and advice to managers to enable the strategy to be implemented.
\end{abstract}

\title{
FINDINGS
}

The Theatres Project provides an example of the way in which middle managers were involved in strategic change, and it illustrates some of the conditions necessary to allow them to take up an enhanced role. On the one hand, the project showed that middle managers can resist deliberate strategy of executive management; on the other, we can see that middle managers can be included in strategic change in a way that enhances their role.

Of particular interest in Theatres was that the implementation of local pay had been tackled in two distinct phases, each reflecting a different approach. During the first phase local pay was high on the national agenda for change in the NHS. However, in the second phase, the election of a new Labour government introduced a great deal of uncertainty regarding intentions towards pay arrangements. In the first phase, the HR Department, in a drive to ensure consistency across the hospital and wanting directorates to implement a generic framework for local pay, took a topdown approach. Only belatedly did it recognize that this approach to strategic 
change, which emphasized the more formal and deliberate elements of strategy, was unlikely to be successful:

In the early days of local pay we drove it from the top but it didn't address their [middle managers] needs and their objectives and therefore they felt that they couldn't support it and take it forward. We did set it up as a very corporate project because it was driven nationally. We did all the classic structural hierarchy things. In retrospect we would have done it differently' [Personnel Manager].

As a result, middle managers were able to resist the generic pay and conditions frameworks, on the basis that they didn't fit operational context. Middle managers in Theatres stressed that:

What we needed in Theatres did not run with what Human Resources wanted to run. They kept saying, 'it was for the whole hospital' and we said, 'well, it won't work for us. We'll have to be an exception on this one. [Clinical Director: Theatres].

Eventually, in the face of middle manager resistance to its top-down imposition, the HR Department allowed the middle managers to have significant influence over local pay and conditions developed for the Theatres area.

At the same time, government policy was increasingly emphasising financial constraint, requesting year-on-year efficiency gains. The HR Department highlighted the impact of this upon strategic change:

It's all about the bottom line today and not necessarily investing in the future. I believe in the longer-term, over five or six years, we could save thousands of pounds by introducing harmonised pay and conditions into nursing by reducing turnover, vacancies, induction but it isn't real money this year [Personnel Manager]. 
As a result of the financial constraints facing the trust, any local pay initiative 'had to make sound business sense' [Director of Human Resources]. Middle managers were therefore more likely to be included in the formulation of strategic change, because 'middle managers input was required at an early stage so that a business case could be made' [Director of Human Resources]. In addition, government policy towards local pay became uncertain and there was no centrally driven prescription in the area. As a result, and in contrast to earlier days when they were driven by the HR Department, both the direction and detail of local pay were driven by middle managers:

We decided what we wanted to do. We mapped people's salaries. We had meetings with our staff in which Human Resources were involved. We wrote forms and letters: 'This is the package. This is your offer' [Specialty Manager: Theatres].

So we went to the board with the Theatres Project fully costed - $£ 30,000$ best case, $£ 60,000$ worst case etc - and worked closely with Theatres management to ensure we met these figures. They [Theatres management] had to be involved right at the start because there was so much nitty gritty work to be done' [Director of Human Resources].

Middle manager involvement was encouraged by a statement in the strategy document that set out a key theme of 'encourag[ing] more flexible working practices aimed at the delivery of quality patient care'. Within this, the main objective was to 'create new roles and review boundaries between jobs on the basis of service needs and effective delivery of care to patients'. The middle managers enjoyed an enhanced role in two ways in relation to this strategic theme. First, they were included in its development, through membership of a working group that formulated 
drafts of the document. This provided boundary-spanning opportunities for middle managers:

I have recently been on a working group - it's a cross-section of the hospital that's looked at the Human Resources Strategy that will take us forward from 1998 for five years, looking at corporate direction and objectives and how we need to develop the workforce to try to achieve that strategic direction. We looked at various drafts of the document and put our comments forward. We weren't actually writing from scratch [Specialty Manager: Theatres].

Second, they both elaborated upon the broad theme set out in formal strategy so that it fitted operational context and developed the means by which such ends were realised. In Theatres the HR Department provided the initial impetus regarding local pay through broad statements in the formal strategy document, but the project would not have succeeded had there not been specific operational problems that local managers wanted to solve. In order to encourage teamworking, for example, 'we would need to produce a rota that would work for both groups [nurses and theatre practitioners] of staff, as a result of which pay and conditions would need to be harmonised' [Theatres Manager]. Therefore Theatre managers 'insisted' that local pay be implemented despite its being put on the backburner nationally:

A long time ago we wanted to do something about it and we were told, 'wait for local pay'. And we sat back and we waited. Nothing progressed. Eventually I think HR got tired of waiting as well and asked for pilot sites. So we said, 'can we be the pilot for local pay?', because we really need to sort this problem of Whitley anomalies [Specialty Manager: Theatres].

Middle managers in Theatres developed a single pay spine and decided how staff would fit into it: 
We decided there would be several bands, gave them numbers and fitted 170 staff into it. The majority of our trained nurses fit into band 6, which is the old nursing grades of $\mathrm{D}$ and $\mathrm{E}$. Our direct entry ODAs [theatre practitioners] come in here [demonstrated on chart as 5], which is a massive jump when they are qualified. Porters, auxilliaries and clerks fit into band 2. We haven't got charge hands, the old A\&C [Administrative and Clerical] 3 grades who might go into band 3 and we don't use 4 at all' [Nurse Manager: Theatres].

\section{DISCUSSION AND CONCLUSIONS}

In this intervention in Edwards Hospital, the HR Department successfully realised its objectives when it worked through and negotiated with middle managers [Barnett et al. 1996; Ulrich 1997]. As a result, middle managers enjoyed an enhanced role in the realization of human resource strategy in two of the ways identified by Floyd and Wooldridge [1992, 1994, 1997]: through increased discretion in 'implementing deliberate strategy', because they determined the means to meet broad ends; and through 'synthesising information' to contribute towards the initial formulation of those broad ends. Their contribution in these roles came about because of their knowledge of operational context.

Influence such as this, which was integrative with corporate strategy, appeared more appropriate on the basis that it did not alter the overall direction of the organization but was instead concerned to leverage resources within it. While it might not represent influence upon broad corporate strategy, it represents influence upon the strategic subsystem level of Edwards Hospital. The way in which theatre practitioner and nurse performance was linked to pay, the stretching of resources, and the fact that it matched demands from customers for patient-focused care, all gave the theatre services in Edwards some advantage over neighbouring hospitals.

Taking into account the corporate strategy that local pay be introduced, middle managers worked out the impact of local pay upon budgets to make a business case 
for its introduction. The role of the HR Department was initially one of providing a broad philosophy and framework within which middle manager discretion would determine the details. Even in this, middle managers from all areas of the hospital were involved as working group members, and it was middle managers who developed the single pay spine. They also worked out implications for individual's pay, managed the problems associated with this, and developed the appeals mechanisms for staff.

It should be noted that while there was emergent strategic change that emanated from middle managers in Edwards Hospital, such influence was more likely where it was consistent with the corporate vision, which in turn was determined by an increasingly prescriptive central government policy. For example, central government policy, initially at least, encouraged trusts to adopt local pay as part of a more business-like approach to health care provision but, at the same time, required that change be cost-neutral as part of a drive for efficiency gains.

To help ensure consistency with central government policy, the HR Department provided frameworks, such as the formal HR strategy, within which emergent change could took place. As a result, to ensure convergence between emergent strategic change and the dictates of central government there appeared little opportunity for middle managers to take on a divergent role of 'facilitating adaptability' or 'championing alternatives' [Floyd and Wooldridge, 1992, 1994, 1997].

Thus we can see that middle managers can enjoy considerable influence in the realisation of strategic change in the area of human resource strategy. This influence lies in the roles of implementing deliberate strategy and synthesising information. To help overcome external constraints and for middle managers to enjoy an enhanced role, certain characteristics of organisational context may need to 
be present. What we have seen as helpful in this case is that strategic change combined deliberate and emergent elements and the formulation and implementation of strategic change were intertwined.

So what of the future role of middle managers in strategic change? There is a growing body of work in the general management literature that suggests middle managers can add value to organisations [Frohman and Johnson 1993; Smith 1997]. While the majority of academic commentators in the health services management field have not noted this, the findings from this case illustrate that middle managers can take on an enhanced role. Furthermore, although we are in the early days of the Labour Government reforms, there does appear to be a shift towards more collaborative relationships between purchasers and providers, in which networks rather than markets or hierarchies are emphasised [Hunter 1998; Kirkpatrick 1999; Rhodes 1997]. While the growth of the networking phenomenon has paradoxically been the result of central government intervention [Ferlie and Pettigrew, 1998], an enhanced middle manager role in the new arrangements may require that central government intervene less than during previous reforms. Whether the current government is less likely than the previous administrations to intervene is questionable. As Klein [1999: 9] notes, 'Labour's new NHS represents a reversion to a command and control model'. Further, the Labour government is committed to budget austerity and to a greater visibility for performance in the NHS. This may work against an enhanced role for middle managers. 


\section{REFERENCES}

Bach, S. (1994), "Restructuring the personnel function: the case of NHS trusts", Human Resource Management Journal, 5(2), 99-115.

Barnett, S., D. Buchanan, M. Patrickson and J. Maddern (1996), "Negotiating the evolution of the HR function: practical advice from the health care sector", Human Resource Management Journal, 6(4), 18-37.

Bower, J. (1970), Managing the Resource Allocation Process, Harvard University Press, Cambridge MA.

Burgelman, R. (1983a), "A model of the interaction of strategic behaviour, corporate context, and the concept of strategy", Academy of Management Review, 8(1), 61-70.

Burgelman, R. (1983b), "A process model of internal corporate venturing in a diversified major firm”, Administrative Science Quarterly, 28, 223-244.

Caines, E. (1990), "Time to grow up: message from the top for NHS personnel managers", Personnel Management, August, p.12.

Currie, G. (1999a), "Resistance around a management development programme: negotiated order in a hospital trust", Management Learning, 30(1), 43-62.

Currie, G. (1999b), "The Influence of middle managers in the business planning process", British Journal of Management, 10(2), 141-156.

Currie, G. (2000), 'The role of middle managers in strategic change - the case of marketing in the NHS", Public Money and Management, 20(1), 17-21.

Department of Health and Social Security (DHSS) (1983), NHS Management Inquiry (Griffiths Report), HMSO, London.

Drucker, P. (1988), "The coming of the new organization", Harvard Business Review, 66(1), 45-53.

Floyd, S. and B. Wooldridge (1992), "Middle management's strategic influence and organisational performance", Journal of Management Studies, 34(3), 465-485.

Floyd, S. and B. Wooldridge (1994), "Dinosaurs or dynamos? Recognising middle management's strategic role", Academy of Management Executive, 8(4), 47-57.

Floyd, S. and B. Wooldridge (1997), "Middle management's strategic influence and organisational performance", Journal of Management Studies, 34(3), 465-485.

Frohman, A. and L. Johnson (1993), The Middle Management Challenge: Moving from Crisis to Empowerment, McGraw-Hill, New York.

Guest, D. and R. Peccei (1992), The Effectiveness of Personnel Management in the $\underline{\mathrm{NHS}}$, NHS Personnel Development Division, London. 
Guest, D. and R. Peccei (1994), "The nature and causes of effective human resource management", British Journal of Industrial Relations, 32(3), 219-241.

Hancock, C. (1994), "Managers out for the count", Health Service Journal, 105, 5384, p. 17.

Health Service Journal (1994a), "Experts warn against lack of leadership in the NHS", 104, 5427, p. 3.

Health Service Journal (1994b), "The first lesson for Margaret Beckett”, 104, 5427, p. 15.

Hunter, D. (1998), "Putting the national in the NHS", Health Service Journal, 108, 5590, p 18.

Kanter, R. (1982), "The middle manager as innovator", Harvard Business Review, July-August, 95-105.

Kanter, R. (1983), The Change Masters: Corporate Entrepreneurs at Work, Routledge, London.

Kanter, R. (1989), When Giants Learn to Dance, Simon \& Schuster, New York.

Kirkpatrick, I. (1999), "The worst of both worlds? Public services without markets or bureaucracies", Public Money and Management, 19(4), 7-14.

Klein, R. (1999), “Grating expectations”, Guardian, 20 October, pp 8-9.

Mintzberg, H. and J. Waters (1985), "Of strategies deliberate and emergent", Strategic Management Journal, 6, 257-272.

Nonaka, I. (1988), "Towards middle up/down management: accelerating information creation", Sloan Management Review, 29, 9-18.

Nutt, P. (1987), "Identifying and appraising how managers install strategy", Strategic Management Journal, 8, 1-14.

Peters, T. (1987), Thriving on Chaos, Harper \& Row, New York.

Peters, T. (1992), Liberation Management, Macmillan, New York.

Pettigrew, A. (1985), The Awakening Giant, Blackwell, Oxford.

Pettigrew, A., E. Ferlie and L. McKee (1992), Shaping Strategic Change, Sage, London.

Poole, M. (1990), “Editorial: HRM in an international perspective", International Journal of Human Resource Management, 1(1), 1-15. 
Procter, S. and G. Currie (1999), "The role of the personnel function: roles, perceptions and processes in an NHS trust", International Journal of Human Resource Management, 10(6), 1077-1091.

Rhodes, R. (1997), "From marketization to diplomacy: it's the mix that matters", Paper to Public Service Research Unit Annual Conference, Cardiff Business School, Cardiff.

Schendel, D. and C. Hofer (1979), Strategic Management: a New View of Business Policy and Planning, Little, Brown \& Co, Boston MA.

Schilit, W. (1987), "An examination of the influence of middle level managers in formulating and implementing strategic decisions", Journal of Management Studies, 24, 271-293.

Sisson, K. (1990), "Introducing the Human Resource Management Journal", Human Resource Management Journal, 1(1), pp. 1-11.

Smith, V. (1997), Managing in the Corporate Interest: Control and Resistance in an American Bank, University of California Press, Berkeley CA.

Storey, J. (1992), Developments in the Management of Human Resources, Blackwell, Oxford.

Ulrich, D. (1997), Human Resource Champions, Harvard Business School Press, Boston MA. 